\title{
Laser Cutting of Materials of Various Thicknesses
}

\author{
Martin Grepl ${ }^{1}$, Marek Pagáč ${ }^{1}$, Jana Petrů ${ }^{1}$ \\ ${ }^{1}$ VŠB - Technical University of Ostrava, Faculty of Mechanical Engineering, Department of Machining and Assembly, \\ 17. listopadu 15/2172, 70833 Ostrava, Czech Republic
}

Correspondence to: martin.grepl.st@vsb.cz

\begin{abstract}
Thise paper deals with the application of laser technology and optimizing the parameters for cutting nickel alloy. The theoretical part of the paper describes various types of lasers, their principles and usage. The experimental part focuses on optimizing the section parameteres of Haynes 718 alloy using a $\mathrm{CO}_{2}$ gas laser. This alloy is employed in the production of components for the aircraft industry. The experiment was performed on the Wibro Delta laser system designed for sizable parts. The actual section is measured with respect to its quality and any accompanying side effects that occur during the process. In this case, laser output and cutting speed were the parameters with most influence on the final cut. The summary explains the results achieved in a metallographic laboratory.
\end{abstract}

Keywords: laser, cutting, thickness.

\section{Introduction}

Lasers have found wide application in scientific work in astronomy and in optics, in the investigation of material characteristics and other basic research areas. Other practical applications include optical equipment for eye surgery, use in geodesy and seismography, in welding miniature parts from hard-tomelt materials, in chemistry and metallography during spectral microanalyses, etc.

\section{Laser Cutting}

Laser cutting can be:

- Sublimating - the material is removed primarily by evaporation due to the high intensity of the laser radiation in the cut area;

- Melting — the material is melted by a laser beam in the cut area and blown away by an auxiliary gas. Mainly metallic materials are cut using this process;

- Burning - a laser beam heats the material to its ignition temperature, so it can then burn in an exothermic reaction with the reactive gas (e.g., oxygen), and the slag is removed from the cutting area by an auxiliary gas. Titanium, low carbon and corrosion resistant steels can be cut this way.

Laser cutting, the most established laser material processing technology, is a method for shaping and separating a workpiece into segments of desired geometry. The cutting process is executed by moving a focused laser beam along the surface of the workpiece at a constant distance, thereby generating a narrow cut kerf. This kerf fully penetrates the material along the desired cut contour.

The absorbed energy heats and transforms the prospective kerf volume into a state (molten, vaporized, or chemically changed) which is volatile or which can be removed easily. Normally, removal of the material is supported by a gas jet that, impinges coaxially to the laser beam. This cutting gas accelerates the transformed material and ejects it from the kerf.

This process is successful only if the melt zone completely penetrates the workpiece. Laser metal cutting is therfore generally restricted to thin sections. While cutting has been reported through $100 \mathrm{~mm}$ sections of steel, the process is more typically used on metal sheets $6 \mathrm{~mm}$ or less in thickness.

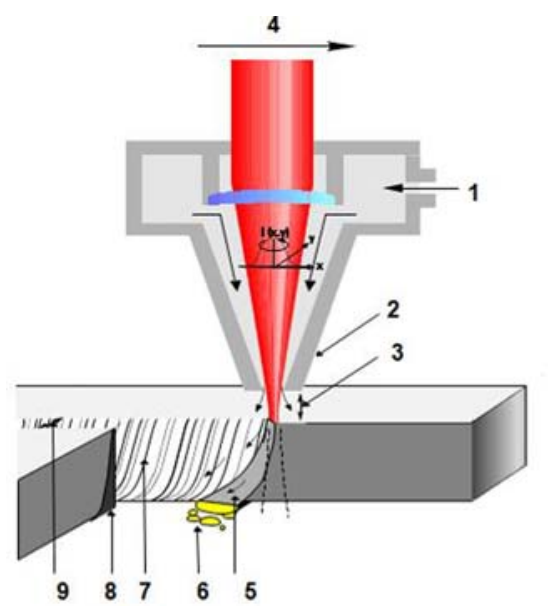

1. Process gas

2. Nozzle

3. Distance from nozzle

4. Cutting speed

5. Molten material

6. Slag

7. Surface roughness

8. Recast layer

9. Width of cut

Figure 1: Principle of laser cutting 
Table 1: Chemical composition of Haynes 718 alloy

\begin{tabular}{|l|c|c|c|c|c|c|c|c|c|c|c|c|c|}
\hline Elements & $\mathrm{Ni}$ & $\mathrm{Co}$ & $\mathrm{Fe}$ & $\mathrm{Cr}$ & $\mathrm{Cb}+\mathrm{Ta}$ & $\mathrm{Mo}$ & $\mathrm{Mn}$ & $\mathrm{Si}$ & $\mathrm{Ti}$ & $\mathrm{Al}$ & $\mathrm{C}$ & $\mathrm{B}$ & $\mathrm{Cu}$ \\
\hline Weight [\%] & 52 & $1^{*}$ & 19 & 18 & 5 & 3 & $0.35^{*}$ & $0.35^{*}$ & 0.9 & 0.5 & 0.05 & 0.009 & $0.1^{*}$ \\
\hline
\end{tabular}

* Maximum

\section{Experimental cutting of materials}

The goal of this experiment was to find suitable cutting parameters when cutting $2.5 \mathrm{~mm}$ and $3.2 \mathrm{~mm}$ metal sheets of this type of alloy using the Winbro Delta laser system. The Winbro Delta manufacturer recommends using this machine for cutting material with a maximum thickness of $6 \mathrm{~mm}$. We also investigated the influence of cutting parameters on the resulting cutting structure from the point of view of shape deformations of the cutting gap and the creation of a recast layer, which is an undesirable accompanying effect of laser cutting.

\section{$2.1 \quad$ Material}

Test samples were made from the Haynes 718 high strength alloy, which belongs to the nickel alloy group. These alloys are suitable for operations under extremely demanding conditions. They are materials that are primarily resistant to high temperatures. These alloys are used in the construction of land gas and aircraft engine turbines, and also for industrial furnaces, combustion chambers, etc. The alloy features outstanding resistance to temperatures from $-253{ }^{\circ} \mathrm{C}$ to $+705^{\circ} \mathrm{C}$, and also excellent resistance against oxidation up to $980^{\circ} \mathrm{C}$.

\section{$2.2 \quad$ Laser system}

The experiment was performed on the Winbro Delta laser system designed for sizable parts up to $1900 \mathrm{~mm}$ in diameter, $500 \mathrm{~mm}$ in height, and up to $500 \mathrm{~kg}$ in weight. The Delta system can be configured with up to four different types of laser sources in order to meet the requirements for specific applications of operational laser technology (e.g., cutting, drilling, or welding) (see Figure 2).

The laser system has been supplemented by the Rofin DC 020 source, and is equipped with the Heidenhain iTNC 530 control system. It is a gas $\mathrm{CO}_{2}$ laser that operates in continuous regime.

\subsection{Cutting parameters}

Samples were made from sheet metal $2.5 \mathrm{~mm}$ and $3.2 \mathrm{~mm}$ in thickness. The laser cutting speed was set to $500 \mathrm{~mm} \cdot \mathrm{min}^{-1}$ based on experimental experience, the distance of the jet from the surface was $0.9 \mathrm{~mm}$, exciting frequency $2000 \mathrm{~Hz}$, filling $75 \%$.

The laser source output was changed by $10 \%$ for each cut, see Tables 2 and 3 .

The cut length was $10 \mathrm{~mm}$. The placement or distances of the cuts were empirically selected so that the gaps between them would be sufficient from the point of view of possible temperature effects on the neighboring cuts.

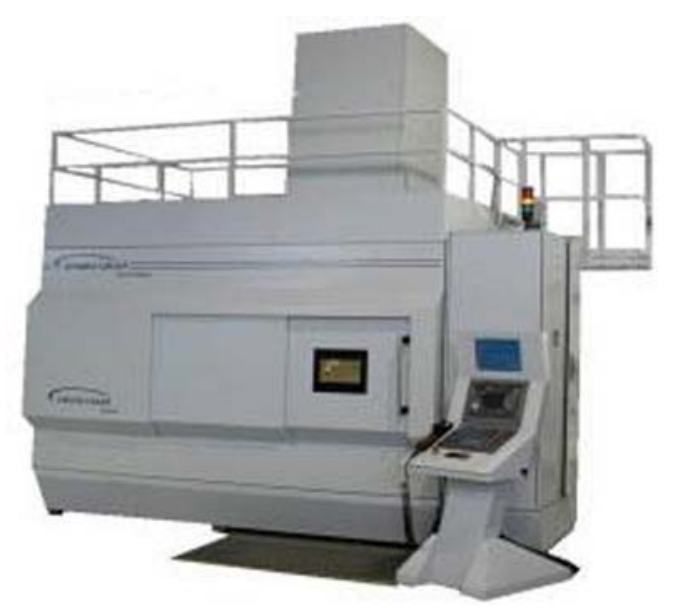

Figure 2: Wibro Delta laser system with the Heidenhain iTNC 530 control system

Table 2: Power of laser (2.5 mm thickness)

\begin{tabular}{|c|c|}
\hline Number of cut & Power of laser $2 \mathrm{~kW}[\%]$ \\
\hline Cut 1 & 90 \\
\hline Cut 2 & 80 \\
\hline Cut 3 & 70 \\
\hline Cut 4 & 60 \\
\hline Cut 5 & 50 \\
\hline Cut 6 & 55 \\
\hline
\end{tabular}

Table 3: Power of laser (3.2 mm thickness)

\begin{tabular}{|c|c|}
\hline Number of cut & Power of laser 2kW [\%] \\
\hline Cut 7 & 90 \\
\hline Cut 8 & 80 \\
\hline Cut 9 & 70 \\
\hline Cut 4 & 60 \\
\hline
\end{tabular}



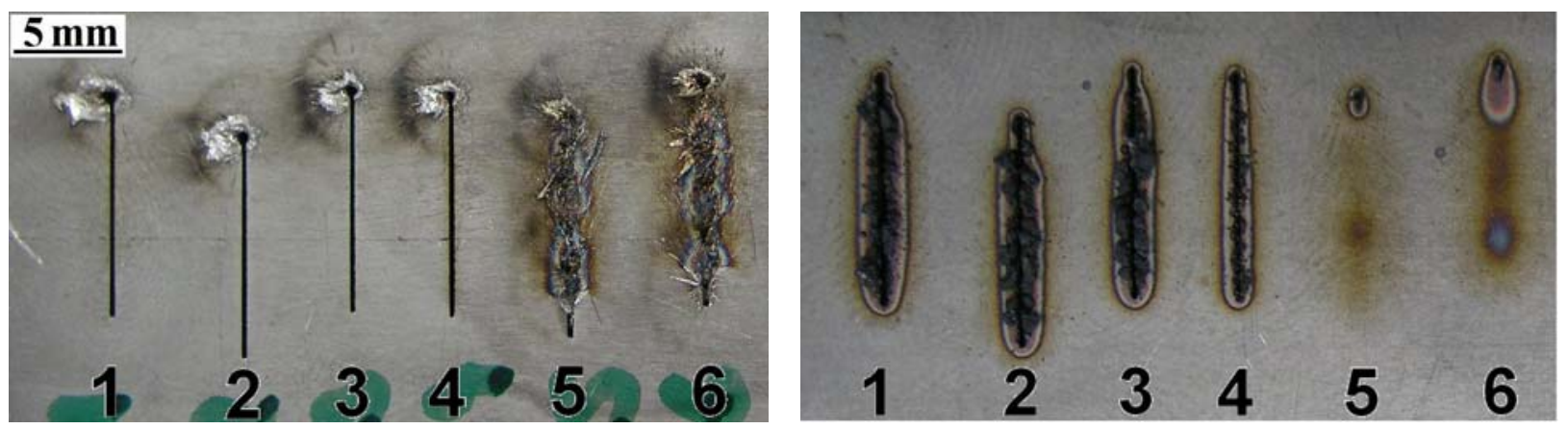

Figure 3: The sample — sheet metal $2.5 \mathrm{~mm}$ in thickness (Haynes 718): a) upper side of the sample, b) underside of the sample

\section{Realization of the experiment}

Cuts nos. 1 to 5 were formed according to the proposed cutting parameters. It was demonstrated that the metal was not completely cut through with the parameters set for no. 5. The output for the cut no. 6 was therefore set to $55 \%$, i.e. for the average value between cuts no. 4 and 5 . However, $55 \%$ power was again not sufficient for cutting the metal. The lowest power useful for this material thickness is $60 \%$ of the maximum source output, which corresponds to laser source output of $1200 \mathrm{~W}$.

Figure $3 \mathrm{a}$ ) shows cuts nos. 1 to 6 . Cuts nos. 1 to 4 went through the whole thickness of the metal. The reason why the last two cuts were unsuccessful was insufficient laser source power.

Figure 3b) shows the apparent temperature influenced cutting area, which decreases with increasing output. Burnt-on slag forms on the bottom part of the cut. This can be considered as an accompanying phenomenon of the cutting process that can be influenced by setting the cut parameters. It can generally be stated that the height of slag that forms does not exceed the thickness of the cut metal, is brittle and breaks.

We then we investigated a suitable cutting speed using the cuts marked by nos. $4 \mathrm{a}$ to $4 \mathrm{f}$, in order to increase the cut quality. The source parameters were set to the values for cut no. 4, and the cutting speed was the only variable. For each cut we increased the cutting speed by $100 \mathrm{~mm} \cdot \mathrm{min}^{-1}$.
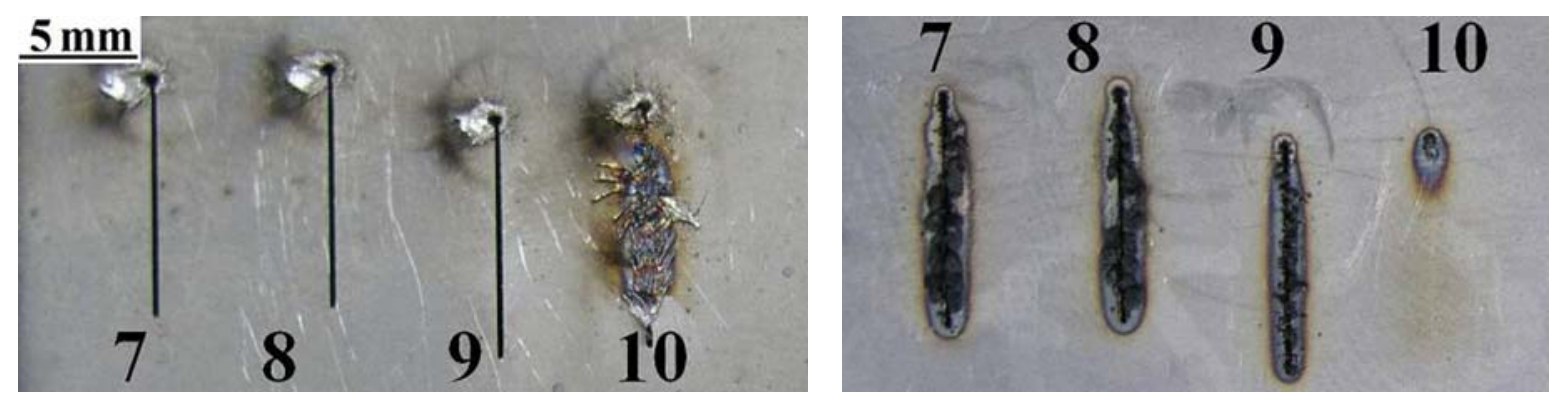

Figure 5: The sample — sheet metal $3.2 \mathrm{~mm}$ in thickness (Haynes 718): a) upper side of the sample, b) underside of the sample 
Table 5: Laser cutting velocities with $80 \%$ power

\begin{tabular}{|c|c|}
\hline Number of cut & $\begin{array}{c}\text { Velocities of laser cutting } \\
{\left[\mathrm{mm} \cdot \mathrm{min}^{-1}\right]}\end{array}$ \\
\hline Cut $8 \mathrm{a}$ & 500 \\
\hline Cut $8 \mathrm{~b}$ & 600 \\
\hline Cut $8 \mathrm{c}$ & 400 \\
\hline Cut $8 \mathrm{~d}$ & 300 \\
\hline Cut $8 \mathrm{e}$ & 450 \\
\hline
\end{tabular}

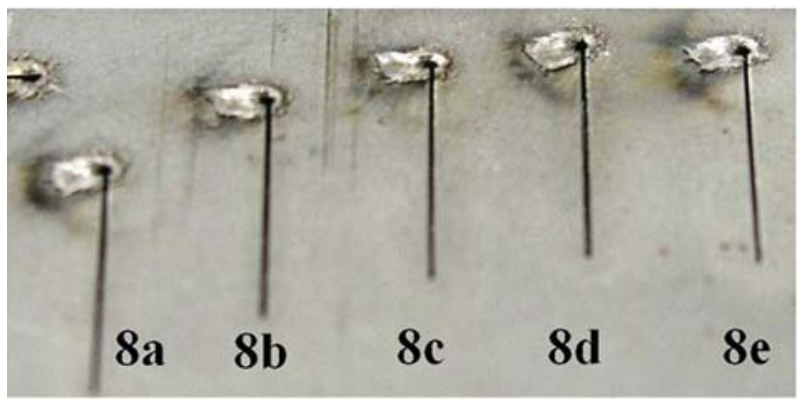

Figure 6: The cuts of variable cutting velocity with constant power $80 \%$

Cuts nos. 7 to 10 were formed according to the proposed cutting parameters. It was demonstrated that the metal was not completely cut through with the parameters set for no. 10. The lowest power useful for this material thickness is $70 \%$ of the maximum source output, which corresponds to laser source output of $1400 \mathrm{~W}$.

Then we investigated a suitable cutting speed, using the cuts marked by nos. $8 \mathrm{a}$ to $8 \mathrm{e}$, in order to increase the cut quality. The source parameters were set to the values of cut no. 8 , and the cutting speed was the only variable. For each cut we changed the cutting speed, see Table 5 .

Cuts nos. 8a and 8c were evaluated as the best from the point of view of cutting quality. These cuts correspond to a cutting speed interval of $\langle 400 ; 500\rangle \mathrm{mm} \cdot \mathrm{min}^{-1}$. In order to make the cutting speed value more exact we performed cut no. $8 \mathrm{e}$ with a cutting speed of $450 \mathrm{~mm} \cdot \mathrm{min}^{-1}$.

\section{Metallographic evaluation}

We made metallographic sections in the metallographic laboratory, and compared the cuts. Figure 7 is a photograph showing a comprehensive view of cut no. 1 (magnified 10 and 50 times, etching agent Vilella), with no recast layer observable, except for an imperceptible layer on the cut walls that probably occurs always. The cut profile is symmetrical, without major shape deformations.
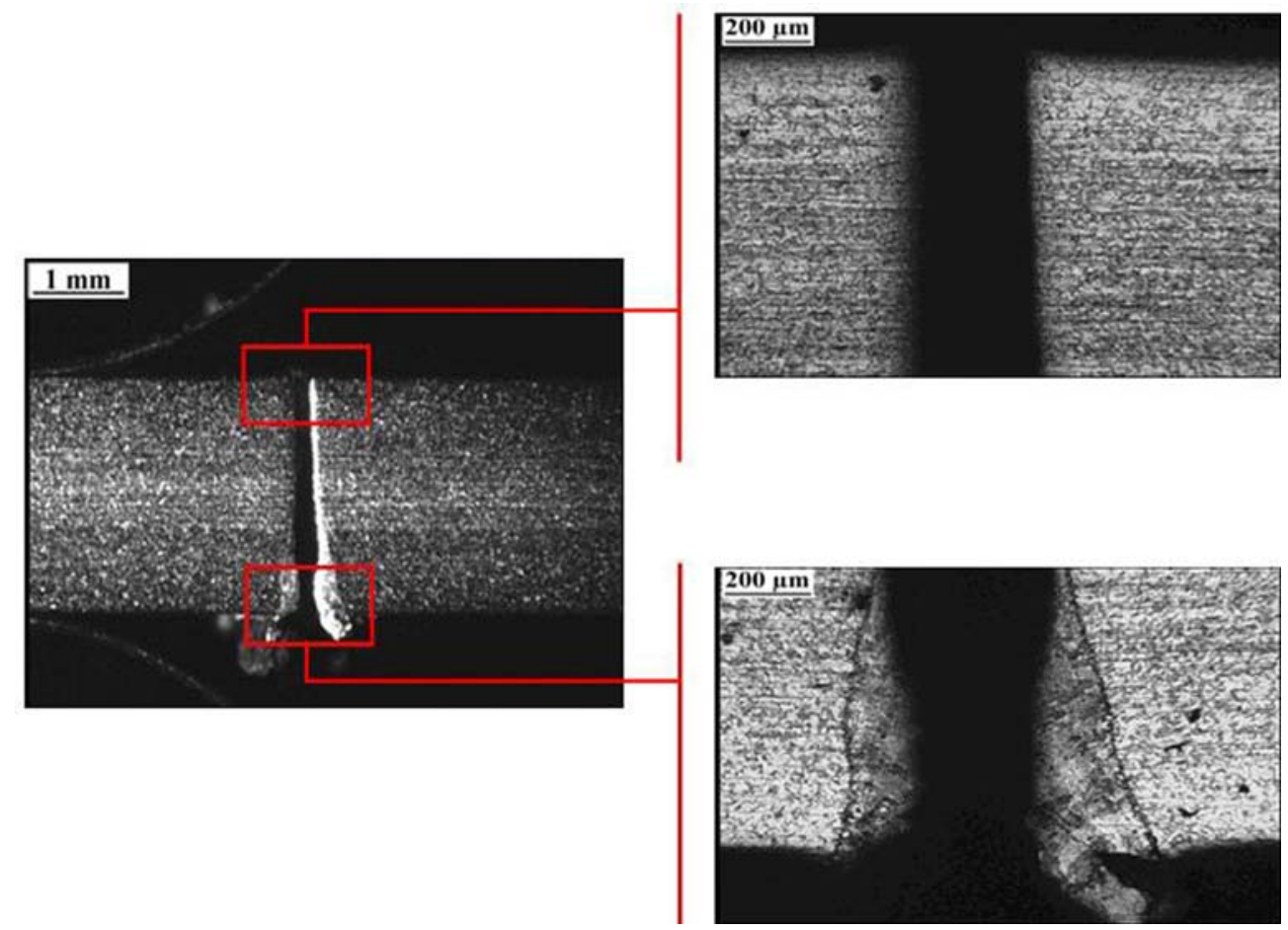

Figure 7: Detail of cut no. 1 (power $90 \%$, cutting velocity $500 \mathrm{~mm} \cdot \min ^{-1}$, magnified $10 \times$ and $50 \times$ ) 


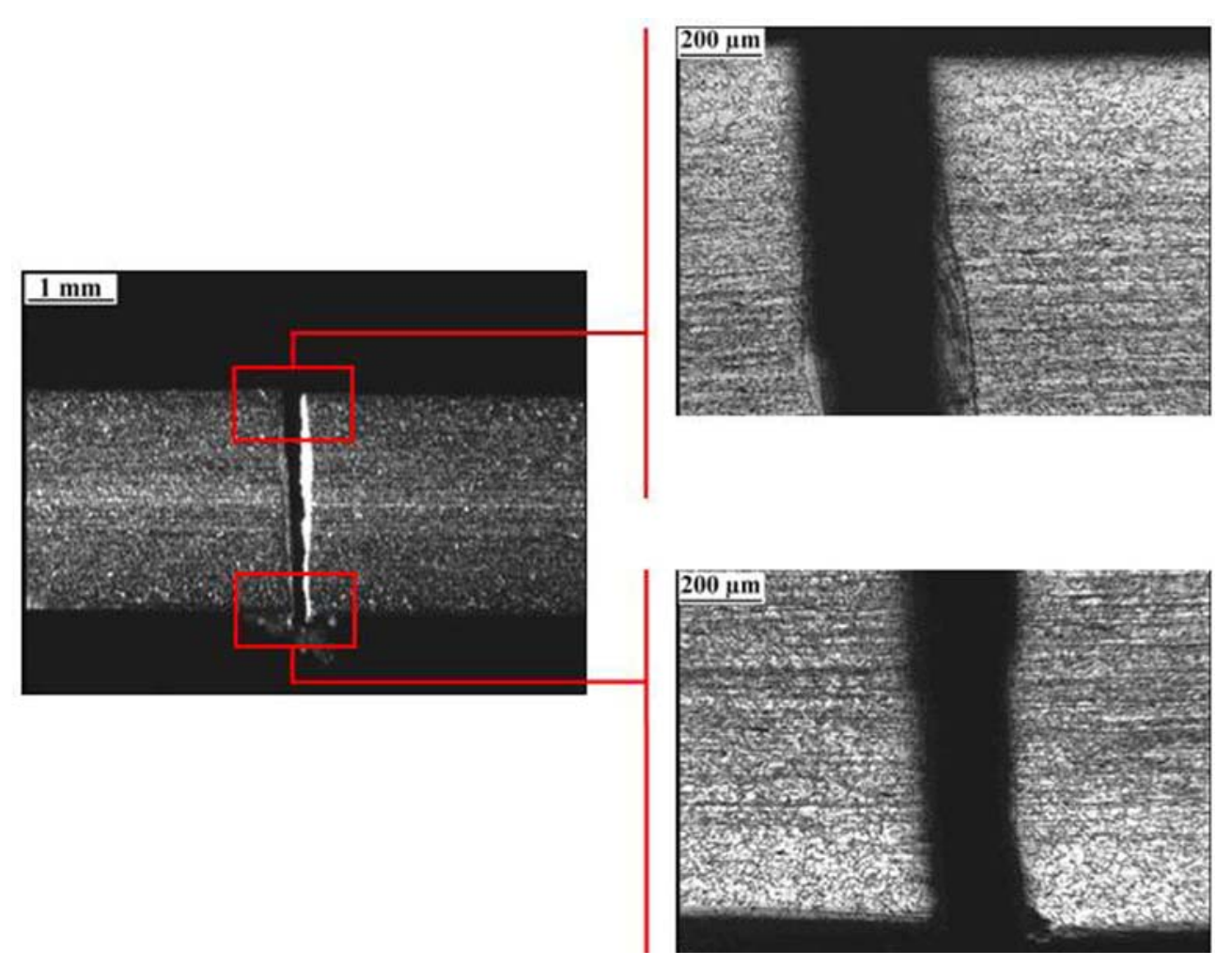

Figure 8: Detail of cut no. 4 (power $60 \%$, cutting velocity $500 \mathrm{~mm} \cdot \min ^{-1}$, magnified $10 \times$ and $50 \times$ )
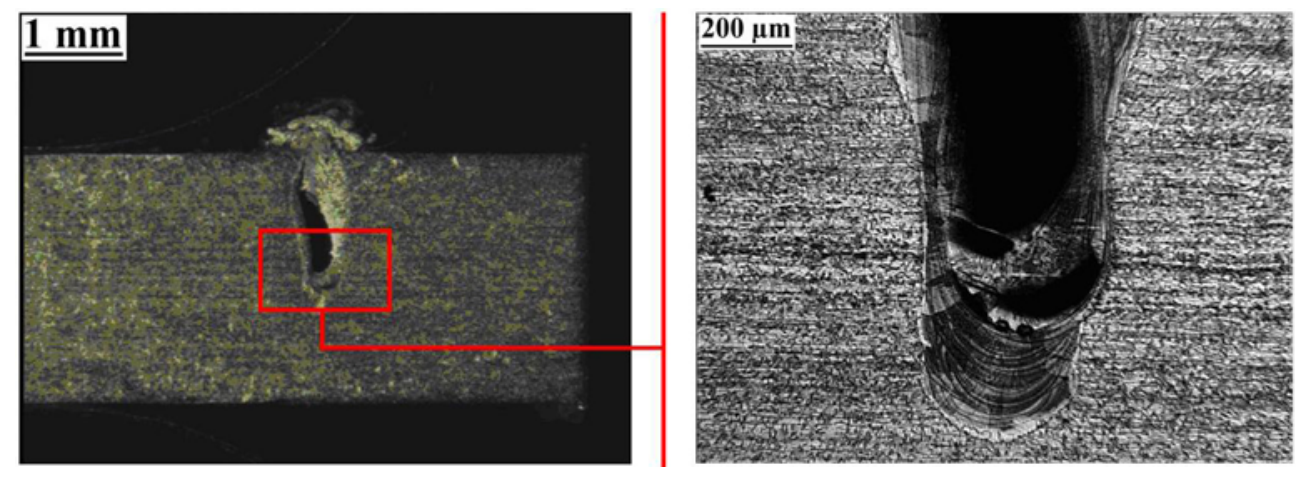

Figure 9: Detail of cut no. 6 (power $55 \%$, cutting velocity $500 \mathrm{~mm} \cdot \mathrm{min}^{-1}$, magnified $10 \times$ and $50 \times$ )

We can see the originating asymmetrical distribution of the recast layer at the bottom of the cut. This layer is caused by the barrier that originates due to the melt concentrated in the bottom part of the cut. The melt after solidification manifests itself as a burr on the bottom edge of the cut. Burrs are not acceptable, and must be removed by milling. Due to this, the heat that originates during cutting, and does not have a chance to dissipate from the surrounding of the cut, accumulates in this location. As a consequence there is local overheating, a change in the shape of the cut, and an increase in the volume of the recast layer.

Cut no. 4 was selected as the best in quality after visual control. It can be seen that it appears satis- factory, even from the point of view of the size of the recast layer.

Figure 9 shows at photograph of cut no. 6, in which the metal was not completely cut through. This is an unacceptable situation, caused by insufficient output of the laser.

\section{Conclusion}

On the basis of experiments, we have found that suitable parameters for cutting Haynes 718 alloy and metal thickness of $2.5 \mathrm{~mm}$ are $60 \%(1200 \mathrm{~W})$ of the laser output and $750 \mathrm{~mm} \cdot \mathrm{min}^{-1}$ cutting speed, according to cut no. 4 f. 
For metal thickness of $3.2 \mathrm{~mm}$, the optimal parameters are $80 \%(1600 \mathrm{~W})$ of the laser output and $450 \mathrm{~mm} \cdot \mathrm{min}^{-1}$ cutting speed, according to cut no. $8 \mathrm{e}$.

To avoid any influence of the surrounding atmosphere on the cut, it is suitable to measure the recast layer using a microprobe, and then to perform a microchemical analysis. We recommend that increased attention be paid to a study of the recast layer and its increased dependence on cutting parameters. It would be suitable to perform the microhardness measurement at the melting boundary of the original material and more importantly, on the recast layer itself. Our paper has contributed a comprehensive view on the influence of the process parameters on a narrow group of materials used in the aerospace industry.

\section{Acknowledgement}

This paper was prepared within the project: Increasing of Professional Skills by Practical Acquirements and Knowledge, no. CZ.1.07/2.4.00/17.0082, supported by the Education for Competitiveness Operational Programme financed by the European Union Structural Funds and with support from the state budget of the Czech Republic.

\section{References}

[1] Gavrilov, P., Jelínková, H., Vrbová, M.: Introduction to Laser Technology. Praha: ČVUT, 1994. 235 p. Faculty of Nuclear Sciences and Physical Engineering. ISBN 80-01-01108-9.

[2] Grepl, M.: Laser Cutting Materials with Variable thickness: master thesis. Ostrava : VŠB - Technical University of Ostrava, Faculty of Mechanical Engineering, Department of Machining and Assembly, 2010, p. 75.

[3] Ready, J. F.: LIA Handbook of Laser Materials Processing. Laser Institute of America, Orlando, FL : Magnolia Publishing, Inc., 2001. Laser Cutting, p. 425-470. ISBN 0-912035-15-3. 